Published in final edited form as:

J Am Chem Soc. 2014 January 22; 136(3): 838-841. doi:10.1021/ja410569g.

\title{
Unusual Kinetic Isotope Effects of Deuterium Reinforced Polyunsaturated Fatty Acids in Tocopherol-Mediated Free Radical Chain Oxidations
}

\author{
Connor R. Lamberson ${ }^{\dagger}$, Libin $\mathrm{Xu}^{\dagger}$, Hubert Muchalski ${ }^{\dagger}$, J. Rafael Montenegro-Burke ${ }^{\dagger}$, Vadim \\ V. Shmanai", Andrei V. Bekish ${ }^{\perp}$, John A. McLean ${ }^{\dagger}$, Catherine F. Clarke ${ }^{\ddagger}$, Mikhail S. \\ Shchepinov $\$,{ }^{*}$, and Ned A. Portert, ${ }^{*}$ \\ tDepartment of Chemistry and Vanderbilt Institute of Chemical Biology, Vanderbilt University, \\ Nashville, Tennessee 37235, United States \\ ‡Department of Chemistry and Biochemistry and the Molecular Biology Institute, UCLA, 607 \\ Charles E. Young Drive East, Los Angeles, California 90095, United States \\ §Retrotope Inc., 12133 Foothill Lane, Los Altos Hills, California 94022, United States \\ "Institute of Physical Organic Chemistry, National Academy of Sciences of Belarus, Minsk \\ 220072, Belarus \\ ${ }^{\perp}$ Department of Chemistry, Belarusian State University, Minsk 220030, Belarus
}

\begin{abstract}
Substitution of $-\mathrm{CD}_{2}-$ at the reactive centers of linoleic and linolenic acids reduces the rate of abstraction of $\mathrm{D}$ by a tocopheryl radical by as much as 36 -fold, compared to the abstraction of $\mathrm{H}$ from a corresponding $-\mathrm{CH}_{2}-$ center. This $\mathrm{H}$ atom transfer reaction is the rate-determining step in the tocopherol-mediated peroxidation of lipids in human low-density lipoproteins, a process that has been linked to coronary artery disease. The unanticipated large kinetic isotope effects reported here for the tocopherol-mediated oxidation of linoleic and linolenic acids and esters suggests that tunneling makes this process favorable.
\end{abstract}

\begin{abstract}
The free radical oxidation of polyunsaturated fatty acids and sterols has attracted attention in recent years since lipid peroxidation is often associated with a variety of human pathologies. The formation of oxidized lipid products is frequently found to accompany heart disease, ${ }^{1,2}$ environmental exposures, ${ }^{3}$ and neurodegenerative disorders, ${ }^{4,5}$ to cite a few examples. Natural antioxidants such as a-tocopherol $(\mathrm{a}-\mathrm{TOH})$ are excellent inhibitors of the free radical chain oxidation reaction in solution, ${ }^{6}$ but antioxidant therapies for many diseases,
\end{abstract}

\footnotetext{
Corresponding Authors. n.porter@vanderbilt.edu, misha@ retrotope.com. ASSOCIATED CONTENT

Supporting Information

1D and 2D NMR spectra, HPLC-MS data, and mass spectra of all the compounds are included in the Supporting Information. This material is available free of charge via the Internet at http://pubs.acs.org.

The authors declare the following competing financial interest(s): M. S. Shchepinov declares a competing financial interest as the Chief Scientific Officer of Retrotope, Inc. The other authors declare no competing financial interests.
} 
while promising in cell culture or even in animal models, have generally been disappointing in clinical studies. ${ }^{7}$

In free radical oxidation in the absence of antioxidants, the chain reaction propagates by the rate-limiting hydrogen atom transfer (Scheme 1, eq 1) and diffusion-controlled oxygen addition to the resulting carbon radical (eq 2). When tocopherol is used as an antioxidant in solution it serves as an $\mathrm{H}$-atom donor to chain-carrying peroxyl radicals, generating a tocopheryl radical (a-TO') in the process (see Scheme 1, eq 3). The tocopheryl radical so generated normally traps a second peroxyl radical, terminating the chain sequence (Scheme 1, eq 4). The tocopheryl radical can maintain the chain sequence, however, by abstracting an $\mathrm{H}$ atom from lipid substrates if the rate of initiation is low and the concentration of tocopherol is high. ${ }^{8}$ This reaction is slightly favored thermodynamically with the bond dissociation enthalpy of the phenolic $\mathrm{O}-\mathrm{H}$ being $77.1 \mathrm{kcal} / \mathrm{mol}$ and the bis-allylic $\mathrm{C}-\mathrm{H}$ being $76.4 \mathrm{kcal} / \mathrm{mol} .{ }^{9}, 10$ This process, first recognized by Stocker, Ingold, and Bowry, ${ }^{8,11,12}$ was designated as tocopherol-mediated peroxidation or TMP and is shown as eq 5 in Scheme 1.

The bis-allylic methylene group of polyunsaturated lipids is particularly vulnerable to radical attack, ${ }^{13-15}$ and a recent strategy to diminish lipid peroxidation in vivo is based on deuterium substitution at the reactive center. ${ }^{16}$ Incubation of yeast with small amounts of 11,11- $\mathrm{D}_{2}$ linoleic acid $\left(11,11-\mathbf{D}_{2}\right.$-Lin), for example, increases the resistance of yeast to oxidative stress, ${ }^{17}$ and the same isotopically reinforced fatty acid diminishes neurodegeneration in a mouse model of Parkinson's disease. ${ }^{18}$

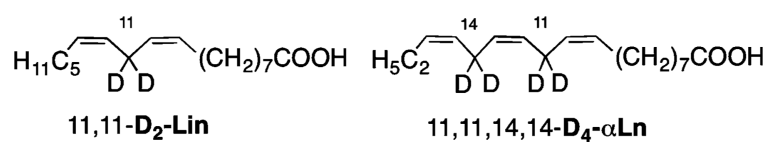

We recently reported that, in the absence of any antioxidants, the propagation rate constant for the oxidation of 11,11-D - -Lin, Scheme 1 eq 1, was some 10-fold less than the propagation constant of the natural fatty acid. ${ }^{19}$ This isotope effect is outside of the range of $k_{\mathrm{H}} / k_{\mathrm{D}}(<7)$ that has been reported for other $\mathrm{H}(\mathrm{D})$ atom transfers from carbon to peroxyl radicals, ${ }^{20,21}$ and it stimulated us to broaden the study of isotope effects in $\mathrm{C}-\mathrm{H}$ free radical transfer reactions. We report here the results of studies of the tocopherol-mediated oxidations of several lipid substrates.

Linoleic acid (Lin), a-linolenic acid ( $a-\mathbf{L n}$ ), and deuterated derivatives of these fatty acids were subjected to azo-initiated free radical autoxidation in the presence of 0.05 to $0.5 \mathrm{M} \mathrm{a}$ tocopherol. The fatty acid concentration was $0.64 \mathrm{M}$, and the initiator was $0.005 \mathrm{M}$ MeOAMVN in benzene at $37{ }^{\circ} \mathrm{C}$. Under these conditions of oxidation in the range of tocopherol concentrations used, a relatively simple mixture of trans, cis conjugated diene products was formed ${ }^{22-24}$ For linoleic acid oxidation under these conditions, the trans, cis conjugated 9- and 13-hydroperoxyoctadecadienoates (HPODEs), were formed in equal amounts; see Scheme 2. The hydroperoxides were reduced to the corresponding hydroxyoctadecadienoates (HODE) before analysis.

Analysis of the 9 and 13 trans, cis HODEs formed from the oxidation of mixtures of linoleic acid and 11,11-- $\mathbf{D}_{\mathbf{2}}$-Lin was carried out by mass spectrometry. Analyses were from at least 
triplicate runs, and each run was analyzed in duplicate. Mass analyses of the HODE products that differ by $m / z=1$ Da was carried out by the collection of product fractions and a full MS analysis. HPLC/MS and typical MS spectra along with fragmentation information are presented in the Supporting Information. Since linoleic acid is significantly more reactive than the deuterated analog, 11,11-D $\mathbf{D}_{\mathbf{2}}$-Lin was used in excesses of up to 10-fold the amount of linoleic acid present in the oxidation mixtures.

The results of these analyses gave $k_{\mathrm{H}} / k_{\mathrm{D}}$ of $23.0 \pm 2.3$ for oxidations of linoleic vs $11,11-\mathbf{D}_{2}$ Lin in the presence of $0.5 \mathrm{M}$ a-tocopherol at $37^{\circ} \mathrm{C}$. Linoleic acid bearing one deuterium and one hydrogen atom at $\mathrm{C} 11,11-\mathrm{D}_{1} \operatorname{Lin}(1.5 \%)$, was present in the $\mathrm{D}_{2}$ substrate as a byproduct of its synthesis, and the value of $k_{\mathrm{H}} / k_{\mathrm{D}}=23.0$ for $11,11-\mathbf{D}_{2}$-Lin should therefore be considered a minimum value. Oxidation of synthetic 11-D $\mathbf{D}_{\mathbf{1}}$-Lin in the presence of $0.5 \mathrm{M} \mathrm{a}$ tocopherol at $37{ }^{\circ} \mathrm{C}$ gave a value of $k_{\mathrm{H}} / k_{\mathrm{D}}=8.9 \pm 0.2$. This intramolecular KIE is due to abstraction of either an $\mathrm{H}$ or $\mathrm{D}$ from a -CHD-, and it represents a different competition than abstraction of an $\mathrm{H}$ from - $\mathrm{CHH}$ - vs a D from - CDD- as is the case for the intermolecular competition of $\mathbf{L i n}$ vs 11,11-D 2 -Lin.

a-Linolenic acid was oxidized in the presence of a-tocopherol to give four conjugated diene hydroperoxides with $\mathrm{OOH}$ substitution at C-9, $-12,-13$, and -16 . Abstraction of the C-11 hydrogen leads to the 9 and 13 hydroperoxides, while $\mathrm{C}-14$ abstraction gives the 12 and 16 products. The ratio of $\mathrm{C}-11$ to $\mathrm{C}-14$ abstraction was found to be 1.05 to 1.00 by product analysis in co-oxidations of a $\mathbf{L n}$, and a-tocopherol. A comparison of the four conjugated diene products formed from the oxidation of mixtures of a-linolenic acid and 11,11,14,14$\mathbf{D}_{4}$-aLn with $0.5 \mathrm{M}$ a-tocopherol at $37{ }^{\circ} \mathrm{C}$ gave $k_{\mathrm{H}} / k_{\mathrm{D}}$ of $32.3 \pm 3.2$. These values of $k_{\mathrm{H}} / k_{\mathrm{D}}$ determined for $\mathbf{H}_{\mathbf{4}} / \mathbf{D}_{\mathbf{4}}$ - $\mathbf{\alpha} \mathbf{L n}$ were based on the analysis of products that differ by $\mathrm{m} / \mathrm{z}=3 \mathrm{Da}$, minimizing any MS corrections needed.

Figure 1 presents UV $(235 \mathrm{~nm})$ chromatograms from oxidations of three deuterated alinolenic acids carried out in the presence of $0.5 \mathrm{M}$ a-tocopherol. Oxidation of 14,14- $\mathrm{D}_{2}$

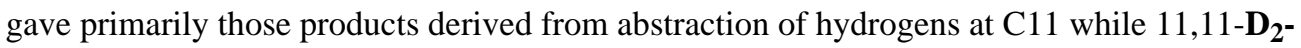
aLn gave products derived from abstraction at $\mathrm{C} 14$ as the major products. 11-D $\mathbf{D}_{\mathbf{1}} \mathbf{- a} \mathbf{L n}$ gave products from either $\mathrm{D}$ or $\mathrm{H}$ abstraction at $\mathrm{C} 11$ that equaled $47 \%$ of the products formed by abstraction of one of the two H's at C14.

Analysis of the product distribution from these experiments, after normalizing to the 1.05:1.00 preference for C-11 to C-14 abstraction in a $\mathbf{L n}$ (see Supporting Information) leads to a $k_{\mathrm{H}} / k_{\mathrm{D}}$ of $35.9 \pm 3.6$ for $14,14-\mathbf{D}_{\mathbf{2}}$ - $\mathrm{a} \mathbf{L n}$ while the value determined for $11,11-\mathbf{D}_{\mathbf{2}}$ - $\mathbf{a} \mathbf{L n}$ is $36.1 \pm 3$.6. Again these values are minimum values for the isotope effect determined by HPLC/UV since $~ 1.5 \%$ of mono-D compound was present in both the 11,11- and 14,14-D compounds. Correction for the contribution of the mono-D compound to the product mixture gives $k_{\mathrm{H}} / k_{\mathrm{D}}$ values about $10 \%$ higher than those reported above. Oxidation of the methyl ester of 11,11-D $\mathbf{D}_{\mathbf{2}}$-aLn under similar conditions as the free acid oxidations gave $k_{\mathrm{H}} / k_{\mathrm{D}}$ values comparable to those of the free acid (see Supporting Information).

Co-oxidation of the deuterated a $\mathbf{L n}$ acids in the presence of $0.05 \mathrm{M}$ a-tocopherol gave $k_{\mathrm{H}} / k_{\mathrm{D}}$ values lower than those determined with $0.5 \mathrm{M}$ a-tocopherol. Thus, $k_{\mathrm{H}} / k_{\mathrm{D}}$ drops to 31 


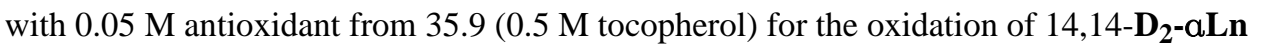
while the corresponding drop of $k_{\mathrm{H}} / k_{\mathrm{D}}$ for $11,11-\mathbf{D}_{2}$ - $\mathrm{\alpha} \mathbf{L n}$ is from 36.1 to 30.9. The concentration dependence is likely the result of the competition between TMP and the peroxyl radical chain reaction, as we have reported a much smaller KIE value for the latter. This observation is supported by previous studies by Bowry and Stocker, who suggested the following: "In strongly inhibited lipid peroxidations with high concentrations of atocopherol and with low rates of initiation, $\mathrm{a}^{-\mathrm{TO}^{*}}$ becomes the main propagating species because the a-TO' terminating reaction (Scheme 1, eq 4) is suppressed by the a-TO' forming reaction (Scheme 1, eq 3)."

Previous studies of kinetic isotope effects (KIE) for several free radical H(D) atom transfers have reported $k_{\mathrm{H}} / k_{\mathrm{D}}>7$, exceeding values expected based on differences in ground-state vibrational energies. The self-exchange transfer of $\mathrm{H}$ or $\mathrm{D}$ from hydroxylamines to nitroxides, for example, has been reported to occur with a $k_{\mathrm{H}} / k_{\mathrm{D}}$ of 20 to 25 , and a theoretical treatment of this reaction indicates significant tunneling in the transfer reaction. ${ }^{25}$ Isotope effects for $\mathrm{H}(\mathrm{D})$ atom transfers from carbon to phthalimide $\mathrm{N}$-oxyl radicals are reported to be as high as $27,{ }^{26-28}$ also indicating that tunneling likely is important in this process. A common element in these reactions with large KIE values appears to be a stabilized and persistent oxygen-centered radical. Tunneling and proton-coupled-electron transfer (PCET) in H(D) atom transfers has also been suggested to play an important role in the soybean lipoxygenase promoted oxidation of linoleic acid, a reaction in which H(D) transfer occurs to an $\mathrm{Fe}^{3+}-\mathrm{OH}$ cofactor. ${ }^{29,30}$ Indeed, PCET has been associated with many enzyme-promoted as well as nonenzymatic transformations that display high H(D) kinetic isotope effects. ${ }^{31}$

The large isotope effects reported here for fatty acid autoxidation in the presence of atocopherol do not have precedent in solution autoxidations, and they are observed (KIE 30) only when the comparison is between centers having geminal substitution of hydrogen ($\mathrm{CH}_{2}-$ ) vs deuterium $\left(-\mathrm{CD}_{2}-\right)$ at the reactive carbon. This geminal effect is significantly attenuated (KIE 8-10) when the competition is between the transfer of $\mathrm{H}$ or $\mathrm{D}$ from the same carbon as in the case of 11-D $\mathbf{D}_{\mathbf{1}}$-Lin.

Tocopherol-mediated peroxidation has been suggested to play an important role in the oxidative modification of human low-density lipoproteins (LDL). Cholesterol linoleate is the major lipid present in the core of LDL particles, which also have appreciable levels of atocopherol and provide a favorable setting for TMP. If a tocopheryl radical is generated in an LDL particle, termination occurs only when another radical is encountered within the particle. This serves to extend the radical lifetime and makes $T M P$ an important pathway for LDL oxidative modification.

The kinetics of TMP has been the subject of several publications, and its importance in the peroxidation of human LDL and its role in human health have been extensively debated. ${ }^{32-34}$ The effect of isotopic substitution on the rate of tocopherol-mediated linoleate peroxidation suggests that $\mathrm{H}$-tunneling plays a significant role in this reaction and therefore also in the oxidative modification of LDL. 


\section{Supplementary Material}

Refer to Web version on PubMed Central for supplementary material.

\section{ACKNOWLEDGMENTS}

This work was supported by a grant from the National Science Foundation to NAP (NSF CHE-1057500).

\section{REFERENCES}

1. Berliner JA, Leitinger N, Tsimikas S. J. Lipid Res. 2009; 50:S207. [PubMed: 19059906]

2. Greenberg ME, Li XM, Guqui BG, Qin J, Salomon RG, Hazen SL. J. Biol. Chem. 2008; 283:2385. [PubMed: 18045864]

3. Murphy RC, Johnson KM. J. Biol. Chem. 2008; 283:15521. [PubMed: 18285330]

4. Zhu X, Tang X, Anderson V, Sayre L. Chem. Res. Toxicol. 2009; 22:1386. [PubMed: 19537826]

5. Montine T, Peskind E, Quinn J, Wilson A, Montine K, Galasko D. NeuroMolecular Med. 2011; 13:37. [PubMed: 20632131]

6. Burton GW, Ingold KU. Acc. Chem. Res. 1986; 19:194.

7. Kamat CD, Gadal S, Mhatre M, Williamson KS, Pye QN, Hensley K. J. Alzheimers Dis. 2008; 15:473. [PubMed: 18997301]

8. Bowry VW, Stocker R. J. Am. Chem. Soc. 1993; 115:6029.

9. Pratt DA, Mills JH, Porter NA. J. Am. Chem. Soc. 2003; 125:5801. [PubMed: 12733921]

10. Trenwith AB. J. Chem. Soc., Faraday Trans. 1. 1982; 78:3131.

11. Bowry VW, Ingold KU. Acc. Chem. Res. 1999; 32:27.

12. Ingold KU, Bowry VW, Stocker R, Walling C. Proc. Nat. Acad. Sci. U.S.A. 1993; 90:45.

13. Porter NA. J. Org. Chem. 2013; 78:3511. [PubMed: 23445181]

14. Yin H, Xu L, Porter NA. Chem. Rev. 2011; 111:5944. [PubMed: 21861450]

15. Pratt D, Tallman K, Porter NA. Acc. Chem. Res. 2011; 44:458. [PubMed: 21486044]

16. Shchepinov MS. Rejuvenation Res. 2007; 10:47. [PubMed: 17378752]

17. Hill S, Hirano K, Shmanai V, Marbois B, Vidovic D, Bekish A, Kay B, Tse V, Fine J, Clarke CF, Shchepinov MS. Free Radical Biol. Med. 2011; 50:130. [PubMed: 20955788]

18. Shchepinov MS, Chou VP, Pollock E, Langston JW, Cantor CR, Molinari RJ, Manning-Bog AB. Toxicol. Lett. 2011; 207:97. [PubMed: 21906664]

19. Hill S, Lamberson CR, Xu L, To R, Tsui HS, Shmanai VV, Bekish AV, Awad AM, Marbois BN, Cantor CR, Porter NA, Clarke CF, Shchepinov MS. Free Radical Biol. Med. 2012; 53:893.

[PubMed: 22705367]

20. Russell GA. J. Am. Chem. Soc. 1957; 79:3871.

21. Howard J, Ingold K. Can. J. Chem. 1966; 44:1119.

22. Roschek B, Tallman KA, Rector CL, Gillmore JG, Pratt DA, Punta C, Porter NA. J. Org. Chem. 2006; 71:3527. [PubMed: 16626136]

23. Tallman KA, Pratt DA, Porter NA. J. Am. Chem. Soc. 2001; 123:11827. [PubMed: 11716752]

24. Tallman KA, Rector CL, Porter NA. J. Am. Chem. Soc. 2009; 131:5635. [PubMed: 19331391]

25. Wu A, Mader E, Datta A, Hrovat D, Borden W, Mayer J. J. Am. Chem. Soc. 2009; 131:11985. [PubMed: 19618933]

26. Koshino N, Cai Y, Espenson JH. J. Phys. Chem. A. 2003; 107:4262.

27. Koshino N, Saha B, Espenson JH. J. Org. Chem. 2003; 68:9364. [PubMed: 14629158]

28. Amorati R, Lucarini M, Mugnaini V, Pedulli GF, Minisci F, Recupero F, Fontana F, Astolfi P, Greci L. J. Org. Chem. 2003; 68:1747. [PubMed: 12608787]

29. Knapp MJ, Rickert K, Klinman JP. J. Am. Chem. Soc. 2002; 124:3865. [PubMed: 11942823]

30. Klinman JP. Philos. Trans. R. Soc. London, Ser. B. 2006; 361:1323. [PubMed: 16873120]

$J$ Am Chem Soc. Author manuscript; available in PMC 2015 September 22. 
31. Weinberg DR, Gagliardi CJ, Hull JF, Murphy CF, Kent CA, Westlake BC, Paul A, Ess DH, McCafferty DG, Meyer TJ. Chem. Rev. 2012; 112:4016. [PubMed: 22702235]

32. Upston JM, Terentis AC, Morris K, Keaney JF Jr, Stocker R. Biochem. J. 2002; 363:753. [PubMed: 11964176]

33. Kathir K, Dennis JM, Croft KD, Mori TA, Lau AK, Adams MR, Stocker R. Free Radical Biol. Med. 2010; 49:481. [PubMed: 20478379]

34. Thomas SR, Stocker R. Free Radical Biol. Med. 2000; 28:1795. [PubMed: 10946221] 

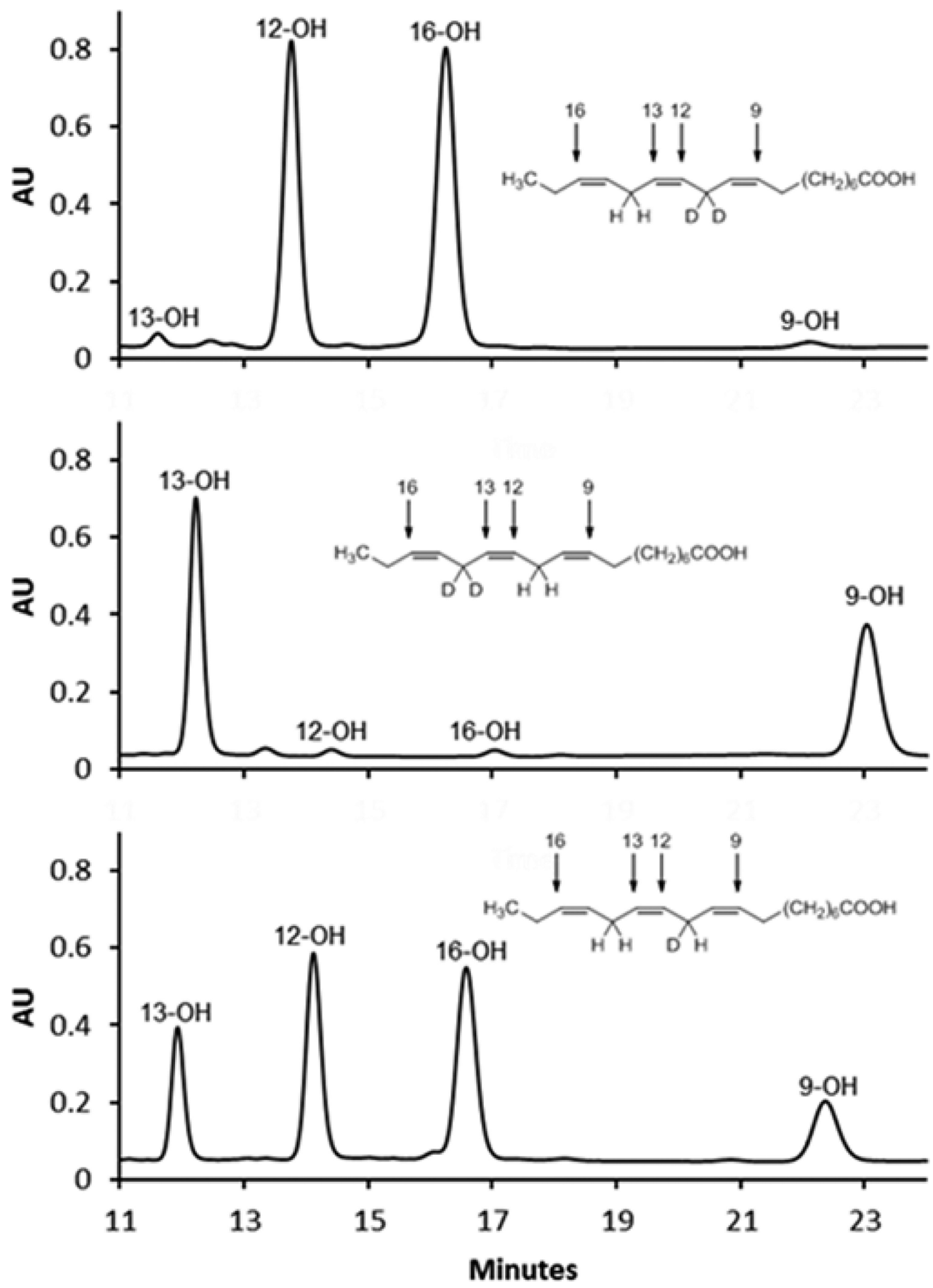

Figure 1.

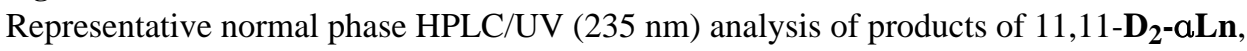

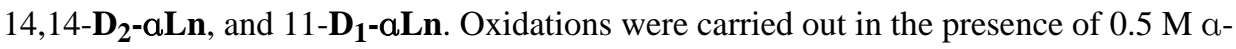
tocopherol at $37{ }^{\circ} \mathrm{C}$ in benzene with MeOAMVN initiator and were followed by reduction of the hydroperoxides to alcohols with $\mathrm{PPh}_{3}$. 


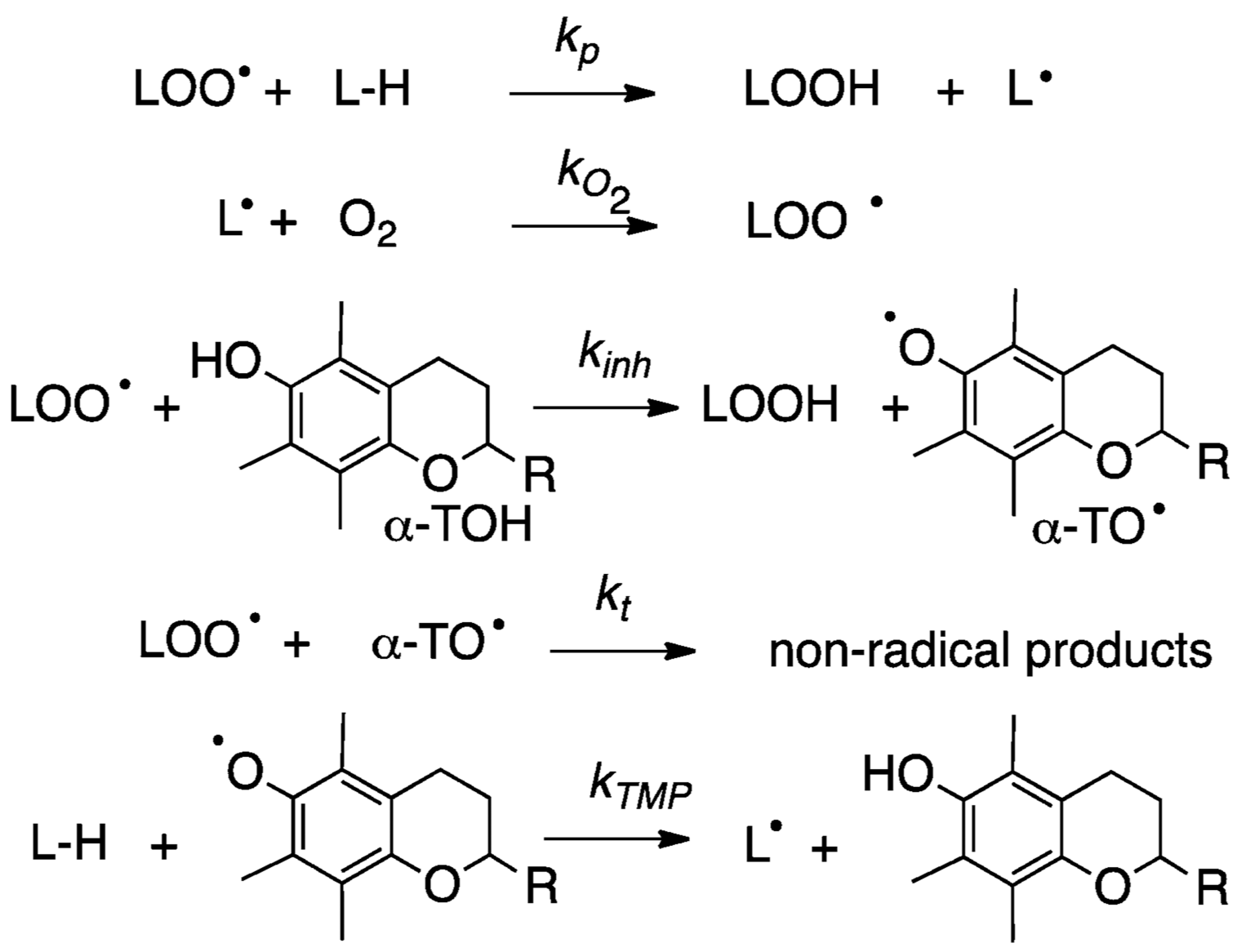

Scheme 1.

Peroxidation, Inhibition, and Tocopherol-Mediated Transformations 


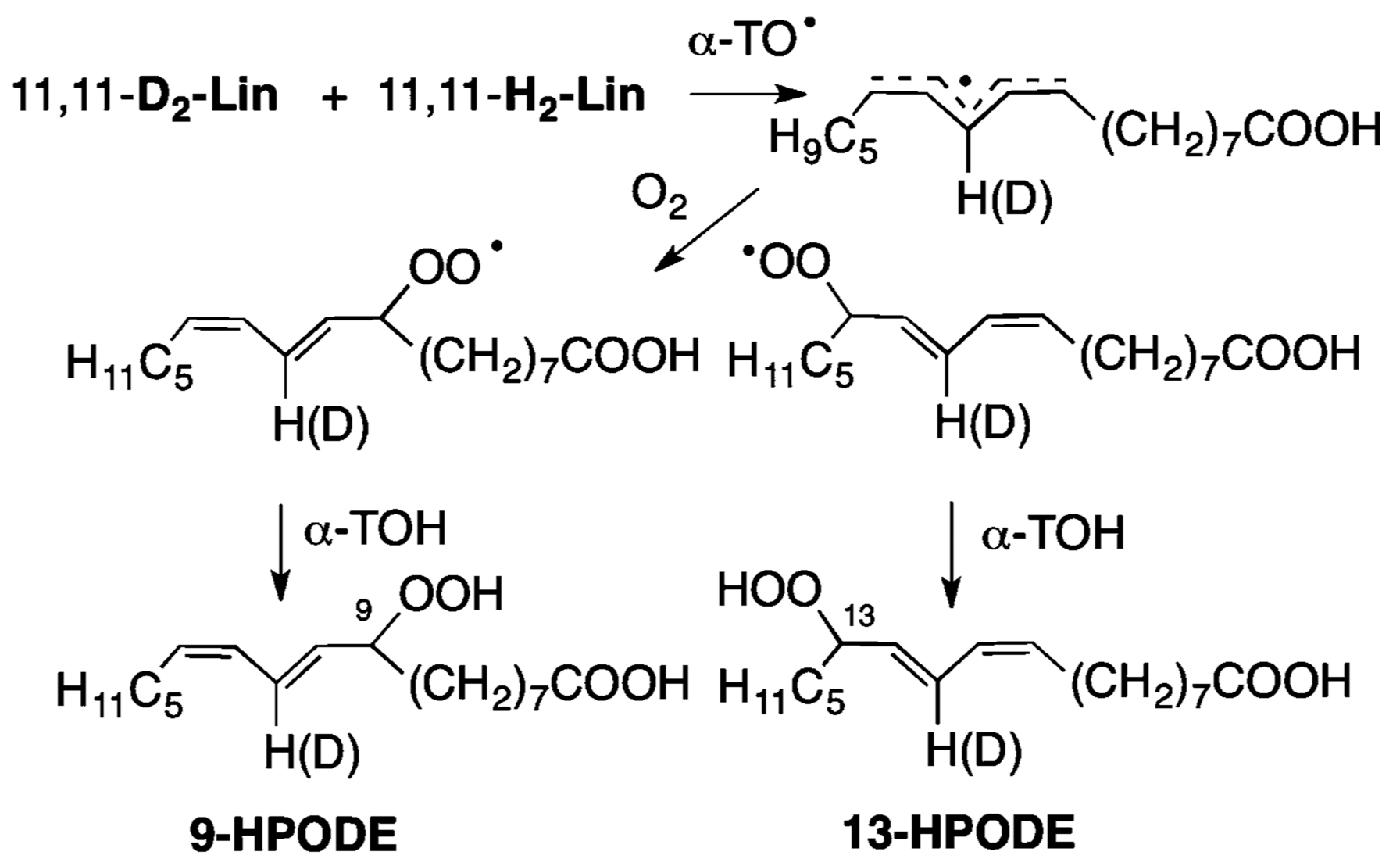

Scheme 2.

Mechanism for Product Formation of Lin Tocopherol-Mediated Peroxidation 